\title{
EVALUATION OF LOCAL RECURRENCE OF BREAST CONSERVATION SURGERY AT THE CEARÁ INSTITUTE OF CANCER
}

\author{
Avaliação da recidiva local da cirurgia conservadora \\ de mama no Instituto do Câncer do Ceará
}

Giovanni de Freitas Magalhães ${ }^{1}$, Francisco Pimentel Cavalcante², Marcos Venício Alves Lima ${ }^{1}$, Rafael Bustamante de Castro ${ }^{3}$

\section{ABSTRACT}

Introduction: Breast cancer is the most common malignant tumor in the world, with the exception of cases of non-melanoma skin cancer. In Brazil, more than 56,000 cases were estimated for 2016. The expected mortality rate remains high because of late diagnosis. Nowadays, conservative surgery is the gold standard treatment. Objective: To evaluate the locoregional recurrence of conservative surgery practiced at the Ceará Institute of Cancer, between 2002 and 2012. Method: A cross - sectional study with a descriptive approach using secondary data obtained from the medical records of patients with breast cancer operated at the Ceará Institute of Cancer. Results: The study population consisted of 360 patients. Invasive ductal carcinoma was the most common type (72.8\%), followed by ductal carcinoma in situ (16.4\%) and invasive lobular carcinoma (4.7\%). The other histological types represent $6.4 \%$ (cribriform, $0.5 \%$, medullary, $0.6 \%$, micro invasive, $0.3 \%$, mucinous, $1.1 \%$, papillary, $3.1 \% 8 \%$; and tubular, $0.8 \%$ ). In the sample, 25 patients had some type of recurrence: 13/360 (3.6\%), local or locoregional; and 12/360 (3.3\%), distant recurrence. Conclusion: From the data analysis, we can conclude that the conservative surgery practiced at the Ceará Institute of Cancer showed data on recurrence compatible with the international literature.

KEYWORDS: Carcinoma, ductal, breast; mastectomy, segmental; recurrence

\section{RESUMO}

Introdução: O câncer de mama é o tumor maligno que mais acomete mulheres em todo o mundo, excetuando-se os casos de pele não melanoma. No Brasil, estimavam-se mais de 56.000 casos para 2016. A mortalidade esperada ainda é alta devido ao diagnóstico tardio. Na atualidade, a cirurgia conservadora é o padrão-ouro. Objetivo: Avaliar a recidiva locorregional da cirurgia conservadora praticada no Instituto do Câncer do Ceará, no período entre 2002 a 2012. Método: Estudo transversal e descritivo, utilizando dados secundários obtidos nos prontuários médicos de pacientes com câncer de mama operadas no Instituto do Câncer do Ceará. Resultados: A população em estudo foi de 360 pacientes. O carcinoma ductal invasivo foi o tipo mais comum (72,8\%), seguido do carcinoma ductal in situ $(16,4 \%$ ) e do carcinoma lobular invasivo $(4,7 \%)$. Os outros tipos histológicos representam 6,4\% (cribiforme, 0,5\%; medular, 0,6\%; microinvasor, 0,3\%; mucinosos, 1,1\%; papilífero, 3,1\%; e tubular, 0,8\%). Na amostra, 25 pacientes tiveram algum tipo de recidiva: 13/360 (3,6\%), local ou locorregional; e 12/360 (3,3\%), recidiva a distância. Conclusão: Da análise dos dados, podemos concluir que a cirurgia conservadora praticada no Instituto do Câncer do Ceará tem dados de recorrência compatíveis com a literatura internacional.

PALAVRAS-CHAVE: Carcinoma ductal de mama; mastectomia segmentar; recidiva.

${ }^{1}$ Ceará Institute of Cancer- Fortaleza (CE), Brazil.

${ }^{2}$ Brazilian Society of Mastology - Fortaleza (UF), Brazil.

${ }^{3}$ Universidade Estadual do Ceará - Fortaleza (CE), Brazil.

*Corresponding author: giovannimedicina@bol.com.br

Conflict of interests: nothing to declare.

Received on: 03/26/2018. Accepted on: 08/20/2018 


\section{INTRODUCTION}

Breast cancer is the most common malignant tumor in the world, with the exception of cases of non-melanoma skin cancer. It is the fifth leading cause of death due to cancer in the world (522,000 deaths). In Brazil, mortality rates from this type of cancer continue to increase. One of the probable factors for the continues growth of these rates is due to late diagnosis. 57,960 new cases are estimated for the year 2016, according to data from the National Cancer Institute (INCA). ${ }^{1}$ Radical surgical treatment for breast cancer was the universally accepted surgery for several decades. Idealized by Willian Halsted, ${ }^{2}$ this surgery removed the entire mammary gland along with the skin and its adjacent tissues, major and minor pectoral muscles, as well as all lymphatic drainage from the axillary region and the neck (supraclavicular fossa).

In 1973, the NSABP B06 study was commenced to evaluate the efficacy of conservative surgery in women with early breast cancer (EC I and II) and tumors $<4 \mathrm{~cm}$. Women were randomized for conservative surgery, with or without radiotherapy and total mastectomy. ${ }^{3,4}$

Between 1973 and 1980 Veronesi et al., independently randomized 701 women with tumors $<2 \mathrm{~cm}$ and clinically negative axilla for a Halstead mastectomy or for conservative surgery with axillary lymph node dissection and radiotherapy. ${ }^{5}$ From the data accumulated in these studies and the research of Veronesi et al. - Milan I and Milan II - ${ }^{5}$ conservative surgery presented with an oncologically safe alternative to radical surgery.

Thus, conservative surgery associated with systemic treatment and radiotherapy has overall survival rates similar to the radical surgery proposed by Halsted over 100 years ago.

The objective of this study is to evaluate the local recurrences and risk factors for recurrences after conservative surgeries performed at the Cancer Institute of Ceará, from 2002 to 2012.

\section{METHOD}

A cross-sectional study with a descriptive approach based on secondary data obtained from medical records of breast cancer patients submitted to conservative surgical treatment with sentinel lymph node biopsy or axillary lymph node dissection at the Ceará Institute of Cancer between 2002 and 2012. Regarding eligibility, a sample of patients with previous breast cancer diagnosis, including those with ductal carcinoma in situ (DCIS), obtained by surgical biopsy or core biopsy, was performed from the study population.

Patients submitted to radical or modified radical surgeries, those whose files had insufficient data, were submitted to neoadjuvant therapies and surgeries performed in case of recurrence or that missed the follow-up, were excluded from the analysis.

The independent variables studied were age, histological type, histological grade, angiolymphatic invasion, tumor dimensions, axillary status, surgical margin, adjuvant treatments performed and local control.

In the sentinel lymph node evaluation, a $0.8 \mathrm{~mL}$ of $99 \mathrm{mTc}$, $29.6 \mathrm{mBq}(0.8 \mathrm{mCi})$ was injected intradermally in the periareolar area, in the four cardinal points of the affected breast. After lymphatic migration, the sentinel lymph node was located with the help of a gamma probe, removed and sent to the pathologist, and then sliced longitudinally, up to $2 \mathrm{~mm}$ along its long axis, subjecting all fractions to histological examination, without immunohistochemical study.

In the evaluation of the breast quadrant, the piece was resected with a macroscopic safety margin of approximately $1 \mathrm{~cm}$ in the palpable lesions and, in the impalpable, with the aid of blue staining or radioguided occult lesion localization (ROLL), in order to maintain the lesion within the resected mammary sector and maintain oncological safety.

All margins of the section were evaluated (cranial, caudal, medial, lateral, deep and superficial). The pathologist measured the tumor and its distance from the margins macroscopically. The edges were frozen and microscopic evaluation was performed. In the case of compromised margins, margin widening was performed, usually at the same surgical time.

The data were stored in the database of the Statistical Package for Social Science (SPSS ${ }^{\oplus}$ ) for Windows, version 21.0. For the characterization of the results, absolute $(\mathrm{N})$ and relative (\%), medium and median frequencies were used. The $\chi^{2}$ test was used in the analysis of association between the categorical variables. For frequencies smaller than five or of small size, this test was replaced by Fisher's exact, when appropriate. The exact values of $p$ were obtained from the distribution of $\chi^{2}$, when applicable, excluding cases categorized as "ignored", "unknown" or "unassessable" of each variable studied. A significance level of $5 \%$ was adopted. This research was registered under process number 011/2012 and was approved by the Research Ethics Committee of the Ceará Institute of Cancer, according to opinion number 61,473, of July 26, 2012.

\section{RESULTS}

The study population consisted of 360 patients with primary breast cancer submitted to conservative surgery. Invasive ductal carcinoma was the most common histological type, with 262 patients (72.8\%), followed by DCIS, with 59 (16.4\%) and invasive lobular carcinoma, with 17 (4.7\%). The other histological types together represent $6.1 \%$ (cribriform, $0.5 \%$, medullary, $0.6 \%$, micro invasive, $0.3 \%$, mucinous, $1.1 \%$, papillary, $3.1 \%$, and tubular, $0.8 \%$ ).

Within the analyzed sample, 25 patients (6.9\%) had some type of recurrence (local, locoregional or distance): 12 (3.3\%), distance; 11(3.1\%), local; and 2 (0.6\%), locoregional. From this recurrence group, 20 (80\%) occurred within the first 5 years of follow-up; $3(0.12 \%)$, between 5 and 10 years of follow-up; and 
$1(0.04 \%)$, with less than 2 years of follow-up. Among the patients with recurrence, 21 (84\%) had invasive cancer (20 with invasive ductal carcinoma - $95.2 \%$ of the cases - and 1 (4.8\%) with invasive lobular carcinoma) and 4(16\%) had DCIS. Among those patients with invasive cancer 11 were alive in the last evaluation (October 2013), 2 left the follow-up and 8 died, with the primary cause of death being breast cancer. Among the patients whose primary cancer was DCIS, 3 were alive (75\%) and 1 (25\%) had died. In the group of patients with recurrences, 2 (8\%) presented compromised margins of the primary cancer in surgery, while $23(92 \%)$ had free margins.

Among the 360 patients in this sample who underwent conservative surgery, 186 (51.7\%) were submitted to a chemotherapy regimen: 29 (8.1\%), adriamycin / cyclophosphamide (AC); 27 (7.5\%), AC with taxanes; 66 (18.3\%), cyclophosphamide, methotrexate and fluorouracil (CMF); 40 (11.1\%), fluorouracil, adriamycin and cyclophosphamide / fluoracil, epirubicin, cyclophosphamide (FAC / FEC); and 9(2.5\%), to other regimes. Within the recurrence group, 21 patients (84\%) underwent chemotherapy and 18 (72\%) had an association with hormone therapy.

Regarding radiotherapy treatment, 42 patients (11.7\%) were not submitted to radiotherapy; the remainder - 318 (88.3\%) - was. In the recurrence group, 22(88\%) received radiotherapy while three patients $(12 \%)$ were not submitted to radiotherapy

SPSS $^{\oplus}$ (version 20.0) was used for the statistical analysis of data. The $\chi^{2}$ test was used to compare the frequencies, or the Fisher's exact test. The level of significance was $95 \%$ - the bilateral $\mathrm{p}$ value $<0.05$ ( $\mathrm{p}<0.05)$ was considered statistically significant.

The analyzed variables were: age, number of positive sentinel lymph nodes, radiotherapy, histological type and degree of primary cancer differentiation, primary and recurrence surgical approach, performed chemotherapy, presence of hormone receptors (estrogen and progesterone), sentinel lymph node with capsular extravasation, axillary lymphadenectomy, clinical and pathological staging of the primary cancer, angiolymphatic invasion, surgical margin and presence of the HER-2 protein.

The only variables in this sample that had a positive association with recurrence were sentinel lymph node with capsular extravasation $(\mathrm{p}=0.044)$ and angiolymphatic invasion $(p=0.057)$ in the Fisher's test. However, due to its characteristics, we can use the likelihood ratio that would give a significant ratio $(X=4,104, p=0.043)$.

In this evaluation, it was expected that there would be a positive relation between the staging of the primary cancer (both pathological and clinical), histological grade, number of positive sentinel lymph nodes, as well as age.

This statistical significance may not have occurred due to the $\mathrm{n}$ that, although significant $(\mathrm{n}=360)$, is presented as a small sample, since, with current treatments, recurrence of breast cancer ranges from 0.5 to $1 \%$ year. Thus, we would need a much larger patient sample for there to be statistical significance.

\section{DISCUSSION}

In the last few decades, the progress in breast cancer treatment has undergone important changes, prolonging the life of patients, as well as the improvement in the quality of life of those patients with this disease.

The role of conservative surgery is well established in the scientific community regarding the association between oncological safety and the esthetic effect.

Veronesi et al. ${ }^{5}$ showed in their study that patients with $\mathrm{T} 1$ / T2 N0M0 primary cancer could undergo conservative surgery and that this treatment modality would not affect overall or disease-free survival. In a study by Milan I, better local control of the disease was found in patients treated with conservative breast surgery and local treatment with radiotherapy. The main disadvantage of conservative breast surgery was local recurrence, which varied from 6 to $16 \%$. Several studies have shown that the rate of local recurrence after conservative surgery is declining. The explanation for this observation is multifactorial, including careful evaluation of the margins, use of more personalized and accurate radiotherapy in the tumor bed, and more patients receiving systemic therapy. ${ }^{6-8}$

The use of new combinations of systemic adjuvant therapies and the use of trastuzumab may have resulted in an additional improvement in local control, especially in young patients. ${ }^{9}$ In a population-based study, Voogd et al..$^{10}$ evaluated the risk trends for local recurrence and the impact of local or distance recurrence on disease-free survival in patients with primary breast cancer aged $<40$ years. The rate of local recurrence declined from $9.8 \%$ in the period $1988-1998$ to $5.9 \%$ between $1998-2005$ and $3.3 \%$ in 2006-2010. ${ }^{8}$

Successful conservative surgery requires the complete removal of the malignant tumor, including a margin of normal breast tissue. This can be challenging since the microscopic spread of cancer can be difficult for the surgeon to discern. The National Comprehensive Cancer Network (NCCN, version 3.2015) ${ }^{11}$ says that adequate surgical margins are those above $10 \mathrm{~mm}$. There is no consensus for the interval between 1 and $10 \mathrm{~mm}$. Margins less than $1 \mathrm{~mm}$ are considered inadequate. In the last consensus by St Gallen, ${ }^{12}$ a margin is considered adequate when it does not touch the ink during the freezing process.

In a retrospective study published in the journal of the international society of surgery, ${ }^{13}$ the margin was not a significant factor regarding the impact of patient survival. The biological characteristics were more important (histological type, hormonal receptors, presence of HER-2 protein and lymph node status).

In the study under analysis, 25 patients $(7.5 \%)$ had some type of recurrence, 13 of which had local or locoregional recurrence (13/360 - 3.6\%) and 12, distance recurrence $(12 / 360-3.3 \%)$, which is in accordance with data from the international literature.

In the analysis of the recurrence group, only 3 patients $(1.2 \%)$ were not treated with radiotherapy. It can be observed that among 
the 360 patients submitted to conservative surgery, $42(11.67 \%)$ did not perform this type of treatment.

Regarding chemotherapy, 174 patients (48.3\%) did not receive chemotherapy treatment. In the recurrence group, 5(20\%) did not undergo treatment with any chemotherapeutic agent.

The current research is limited, to a certain extent, because of the lack of data in relation to Ki 67 , since some patients were not submitted to this analysis because the immunohistochemical studies with all the predictive and prognostic factors only became standard procedure in the institution from 2006. Therefore, an analysis of the molecular classification of these patients is impossible.

\section{CONCLUSION}

Surgery for breast cancer remains in evolution. Over the years, studies have taken us from radical procedures to those with the least mutilation possible and immediate local repair.

It can be concluded from this research that the conservative surgery practiced at the Ceará Institute for Cancer between 2002 and 2012, achieved data on local, locoregional and distance recurrence compatible with the international literature.

We also emphasize the importance of the continuity to this study to contribute to the improvement of the quality of life of the patients, in relation to their image and self-esteem after breast cancer treatment.

\section{REFERENCES}

1. Instituto Nacional do Câncer José Alencar Gomes da Silva. Estimativa, 2016: Incidência de Câncer no Brasil. Rio de Janeiro: Inca; 2016.

2. Halsted WS. The results of radical operations for the cure of carcinoma of the breast. Ann Surg. 1907;46(1):1-19.

3. Fisher B, Montague E, Redmond C, Deutsch M, Brown GR, Zauber A, et al. Findings from NSABP Protocol No. B-04 - comparison of radical mastectomy with alternative treatments for primary breast cancer. I. Radiation compliance and its relation to treatment outcome. Cancer. 1980;46(1):1-13. https://doi.org/10.1002/1097-0142(19800701)46:1\%3C1::AIDCNCR2820460102\%3E3.0.CO;2-3

4. Fisher ER, Anderson S, Redmond C, Fisher B. Ipsilateral breast tumor recurrence and survival following lumpectomy and irradiation: patological findnes from NSABP protocol B-06. Semin Surg Oncol. 1992;8(3):161-6.

5. Veronesi U, Cascinelli N, Mariani L, Greco M, Saccozzi R, Luini A, etal.Twenty-year follow-up of a randomized studycomparing breast-conserving surgery with radical mastectomy for early breast câncer. N Engl J Med. 2002;347(16):1227-32. https://doi. org/10.1056/NEJMoa020989

6. Harlow SP, Krag DN, Julian TB, Ashikaga T, Weaver DL, Feldman SA, et al. Prerandomization surgical training for the NSABP - 32 trial: a randomized phase III clinical trial to comparari sentinel node ressection to conventional axilary disseccion in clinically node - negative breast cancer. Ann Surg. 2005;241(1):48-54.

7. Bhatti AB, Khan A, Muzaffar N, Siddiqui N, Syed A, Shah $M$, et al. Safe negative margin width in breast conservative therapy: results from a population whit a high percentage of negative prognostic factors. World J Surg. 2014;38(11):2863-70. https://doi.org/10.1007/s00268-014-2651-7
8. Van Laan C, Van der Sangen MJ, Poortmans PM, Nieuwenhuijzen GA, Roukema JA, Roumen RM, et al. Local recurrence following breast conserving treatment in women aged 40 years or younger: trends in risk and impact on prognosis in a population - based cohort of 1143 patients. Eur J Cancer. 2013;49(15):3093-101. https://doi.org/10.1016/j. ejca.2013.05.030

9. Munck L, Schaapveld M, Siesling S, Wesseling J, Voogd AC, Tjan-Heijnen VCG, et al. Implementation of trastuzumab in conjunction with adjuvante chemotherapy in the treatment of non-metastatic breast cancer in the Netherlands. Breast Cancer Res Treat. 2011;129(1):229-33. https://doi.org/10.1007/ s10549-011-1451-0

10. van Dongen JA1, Voogd AC, Fentiman IS, Legrand C, Sylvester RJ, Tong D, et al. Long-term results of a randomized trial comparing breast-conserving therapy with mastectomy: European Organization for Research and Treatment of Cancer 10801 trial. J Natl Cancer Inst. 2000;92(14):1143-50.

11. National Comprehensive Cancer Network. Portal [Internet]. Filadélfia: National Comprehensive Cancer Network; 2014. Disponível em: http://www.nccn.org/

12. Coates AS, Winer EP, Goldhirsch A, Gelber RD, Gnant M, Piccart-Gebhart M, et al. Tailoring therapies-improving the management of early breast cancer: St Gallen International Expert Consensus on the Primary Therapy of Early Breast Cancer 2015. Ann Oncol. 2015;26(8):1533-46. https://doi. org/10.1093/annonc/mdv221

13. Greenberg CC, Habel LA, Hughes ME, Nekhlyudov L, Achacoso N, Acton L, et al. Characterization and treatment of local recurrence following breast conservation for ductal carcinoma in situ. Ann Surg Oncol. 2014; 21(12):3766-73. https://doi.org/10.1245/s10434-014-3802-7 